\title{
Systematic genetic array analysis links the Saccharomyces cerevisiae SAGA/SLIK and NuA4 component Tral to multiple cellular
} processes

\author{
Stephen MT Hoke ${ }^{1}$, Julie Guzzo ${ }^{2}$, Brenda Andrews ${ }^{2}$ and \\ Christopher J Brandl*1
}

Address: ${ }^{1}$ Department of Biochemistry, Schulich School of Medicine \& Dentistry, University of Western Ontario, London, N6A 5C1, Canada and ${ }^{2}$ Department of Medical Genetics and Microbiology and the Banting and Best Department of Medical Research, Terrence Donnelly Centre for Cellular and Biomolecular Research, University of Toronto, Toronto, M5S 3E1, Canada

Email: Stephen MT Hoke - shoke@uwo.ca; Julie Guzzo - julie.guzzo@utoronto.ca; Brenda Andrews - brenda.andrews@utoronto.ca; Christopher J Brandl* - cbrandl@uwo.ca

* Corresponding author

Published: 10 July 2008

BMC Genetics 2008, 9:46 doi:10.1 |86/147|-2156-9-46
Received: 10 April 2008

Accepted: 10 July 2008

This article is available from: http://www.biomedcentral.com/I47I-2/56/9/46

(C) 2008 Hoke et al; licensee BioMed Central Ltd.

This is an Open Access article distributed under the terms of the Creative Commons Attribution License (http://creativecommons.org/licenses/by/2.0), which permits unrestricted use, distribution, and reproduction in any medium, provided the original work is properly cited.

\begin{abstract}
Background: Tral is an essential 437-kDa component of the Saccharomyces cerevisiae SAGA/SLIK and NuA4 histone acetyltransferase complexes. It is a member of a group of key signaling molecules that share a carboxyl-terminal domain related to phosphatidylinositol-3-kinase but unlike many family members, it lacks kinase activity. To identify genetic interactions for TRA I and provide insight into its function we have performed a systematic genetic array analysis (SGA) on tral ${ }_{\text {SRR } 3413}$, an allele that is defective in transcriptional regulation.

Results: The SGA analysis revealed II4 synthetic slow growth/lethal (SSL) interactions for

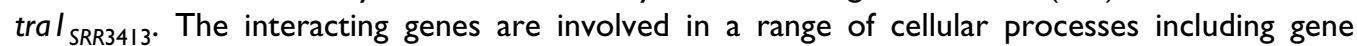
expression, mitochondrial function, and membrane sorting/protein trafficking. In addition many of the genes have roles in the cellular response to stress. A hierarchal cluster analysis revealed that the pattern of SSL interactions for tral ${ }_{S R R 3413}$ most closely resembles deletions of a group of regulatory GTPases required for membrane sorting/protein trafficking. Consistent with a role for Tral in cellular stress, the tra SRR $3413_{3}$ strain was sensitive to rapamycin. In addition, calcofluor white sensitivity of the strain was enhanced by the protein kinase inhibitor staurosporine, a phenotype shared with the Ada components of the SAGA/SLIK complex. Through analysis of a GFP-Tral fusion we show that Tral is principally localized to the nucleus.
\end{abstract}

Conclusion: We have demonstrated a genetic association of Tra I with nuclear, mitochondrial and membrane processes. The identity of the SSL genes also connects Tral with cellular stress, a result confirmed by the sensitivity of the tra $I_{S R R 3413}$ strain to a variety of stress conditions. Based upon the nuclear localization of GFP-Tral and the finding that deletion of the Ada components of the SAGA complex result in similar phenotypes as tra $I_{S R R 34 \mid 3}$, we suggest that the effects of tral SRR3413 are mediated, at least in part, through its role in the SAGA complex. 


\section{Background}

TRA1 is an essential gene in Saccharomyces cerevisiae that encodes a $437 \mathrm{kDa}$ protein product. It is a member of a family of key signaling and regulatory molecules that contain a C-terminal phosphatidylinositol-3-kinase (PI3K) domain [1] and is a component of two multisubunit transcriptional regulatory complexes, the SAGA/SLIK and NuA4 complexes, which also contain the histone acetyltransferase enzymes, Gcn5 and Esa1, respectively [2-4]. Tra1 interacts directly with transcriptional activator proteins and is thought to be critical in recruitment of SAGA/ SLIK and NuA4 to their target promoters [5-8].

Previously we identified mutations in the C-terminal PI3K domain of Tra1 that showed defects in transcriptional activation, sensitivity to ethanol and the cell wall destabilizing agent calcofluor white and resulted in shortened telomeres [9]. The pattern of changes neither fully mimicked those seen upon disruption of other SAGA/SLIK nor NuA4 components. For example, unlike strains with deletions of NuA4 components, the tra1 mutant strains were relatively insensitive to DNA damaging agents. We performed an initial systematic genetic array (SGA) analysis with the most pronounced allele, $\operatorname{tra}_{\text {SRR3413 }}$. This analysis did not identify any synthetic lethal interactions but did reveal 23 synthetic slow growth interactions, many in combination with deletions of genes involved in cell membrane/wall processes. As the lack of synthetic lethal interactions may have arisen from an incomplete selection against diploids in the automated screens, we repeated the screen in a strain background that selects more strongly against diploids. This analysis identified 114 genes displaying synthetic sick/lethal (SSL) interactions with $\operatorname{tra}_{S R R 3413}$. Genes involved in transcription, RNA processing, mitochondrial function and membrane sorting/protein trafficking were prevalent. The phenotypes and genetic interactions of these strains also point to a role for Tra1 in the cellular response to stress.

\section{Results}

\section{SGA analysis of tra ISR SR I3}

As a component of both SAGA and NuA4 complexes, Tra1 is positioned to play a major role in nuclear processes. Previously we performed an SGA analysis on Tra1 using an allele that partially impairs function [9]. No synthetic lethal interactions were obtained in this analysis. We thus chose to repeat the study using a strain that more strongly selects against the spurious appearance of diploids. $\operatorname{tra}_{S R R 3413}$ was integrated into yeast strain BY7092 and SGA analysis performed using the collection of nonessential yeast knockout strains. Haploids were analyzed on synthetic complete (SC) media at $26^{\circ} \mathrm{C}, 34^{\circ} \mathrm{C}$ and $36^{\circ} \mathrm{C}$ with pinnings performed in quadruplicate. 224 double mutant strains, scored as having potential synthetic interactions in each of the screens, were manually tested for growth on YPD media at $30^{\circ} \mathrm{C}$ and SC media at $33.5^{\circ} \mathrm{C}$, after sporulation of the diploids and germination of spore colonies on YPD. For each strain comparisons were made to the relevant single disruption strain. As shown in Table 1, 114 genetic interactions were confirmed as either synthetic lethal or synthetic slow growth on SC or YPD media (SSL interactions). Identified genes are organized according to similarities in associated gene ontology terms. Many cellular functions are represented but the most prominent group were genes linked to membrane sorting/ protein trafficking with an emphasis on vacuolar function. An overlapping group included genes associated with cell wall biogenesis and function. Other groups identified initially were chromosomal functions, RNA processing, gene expression, metabolism and biosynthesis and mitochondrial function. A clear subgroup of a larger chromosomal functions group contained the gene encoding the alternative histone H2AZ (HTZ1) and members of the SWR1 complex, which exchange H2AZ for histone H2A within nucleosomes (for example see [10]).

Before pursuing further analysis of the genes identified in the SGA screen, we wanted to eliminate those that may have arisen through indirect effects on neighboring genes. For instance, YLR111W is a dubious ORF located adjacent to CCW12 that encodes a cell wall component. Since disruption of YLR111W may simply act by affecting expression of CCW12, it was not considered in further analyses. Several other dubious ORFs were eliminated because they overlapped a second identified gene. Other pairs of adjacent genes were $k g d 2$ and num 1, spt8 and erg3, and tpm 1 and $e o s 1$, though these were not removed from the analysis since potentially both could be involved in SSL interactions with tra1 $1_{\text {SRR3413 }}$.

Also indicated in Table 1 is the total number of additional SSL interactions listed for each of the genes in the Saccharomyces Genome Database. It has been argued that the number of interactions may be a measure of the importance of a gene for cellular fitness [11]. The relatively large number of SSL interactions for $\operatorname{tra1}_{\text {SRR3413 }}$ may also reflect its involvement in both SAGA/SLIK and NuA4 complexes. As with any synthetic lethal analysis we can not eliminate the possibility that some of the apparent interactions are due to additive growth defects rather than a demonstration that the genes act in the same or related pathways.

To identify functional relationships for $\operatorname{tra} 1_{S R R 3413}$, a hierarchal cluster analysis of SSL $\mathrm{tra}_{\text {SRR3413 }}$ interactions was performed with the data sets of Tong et al. [11], Measday et al. [12], Reguly et al. [13], Pan et al. [14] and Mitchell et al. [15] plus the SSL interactions of additional SAGA/ SLIK and NuA4 components as listed in the Saccharomyces Genome Database (Figure 1). tra1 $1_{S R R 3413}$ clustered most closely to a group including arl1 0 , arl3 0, gyp 10 , 
Table I: Genes with synthetic slow growth or synthetic lethal interactions with tra I SRR34I3

\begin{tabular}{|c|c|c|c|c|c|c|c|}
\hline GENEI & Orf & $\mathbf{S S L}^{2}$ & $\mathbf{G O}^{3}$ & Location, component ${ }^{4}$ & phenotype $^{5}$ & stress $^{6}$ & $\#^{7}$ \\
\hline MCKI & YNL307C & SL & 1,3 & cytoplasm, nucleus & & $x$ & 28 \\
\hline$C D C 73$ & YLR4I8C & s & $1,3,10$ & Cdc73/Paf complex, nucleus & $\mathrm{T}, \mathrm{R}$ & $x$ & 159 \\
\hline CSE2 & YNROIOW & $S$ & $1,3,10$ & mediator complex & $\mathrm{R}$ & $x$ & 19 \\
\hline HTZI & YOLOI2C & $S$ & $1,3,10$ & nucleus & & & 186 \\
\hline LEOI & YORI23C & $\underline{s}$ & $1,3,10$ & Cdc73/Paf complex, nucleus & $\mathrm{T}$ & & 39 \\
\hline RAD52 & YML032C & $\underline{\mathrm{s}}$ & $1,3,10$ & nucleus & & $x$ & 196 \\
\hline SPT8 & YLR055C & s & $1,3,10$ & SAGA complex, nucleus & & & 62 \\
\hline SRB2 & YHR04IC & s & $1,3,10$ & Srb-mediator complex & $\mathrm{T}, \mathrm{E}$ & & 34 \\
\hline SWRI & YDR334W & s & $1,3,10$ & SWRI complex, nucleus & $\mathrm{R}$ & & 112 \\
\hline VPS7I & YML04IC & s & $1,3,10,9$ & SWRI complex, nucleus & $\mathrm{E}$ & & 97 \\
\hline VPS72 & YDR485C & s & $1,3,10,9$ & SWRI complex, nucleus & $\mathrm{E}$ & & 87 \\
\hline KAR3 & YPRI4IC & s & $\mathrm{I}, 3,7$ & microtubule, spindle pole body & $E$ & & $13 \mid$ \\
\hline UBI4 & YLL039C & s & $1,3,8,9$ & cytoplasm & & $x$ & 7 \\
\hline UBPI5 & YMR304W & s & $1,3,8,9$ & cytoplasm & & & 0 \\
\hline SWC3 & YALOIIW & s & $1,3,9,10$ & SWRI complex, nucleus, mitochondrion & & & 85 \\
\hline DOAI & YKL2I3C & s & $1,9,8$ & cytoplasm, nucleus & & $x$ & 26 \\
\hline TORI & YJR066W & S & $1,2,3,4,5,6,7,8,9,10$ & cellular membranes & $\mathrm{R}$ & $x$ & 27 \\
\hline CKB2 & YOR039W & s & $1,2,3,4,5,7,8,9,10$ & protein kinase CK2, CURI complex & & $\mathrm{x}$ & 14 \\
\hline SNFI & YDR477W & s & $1,3,4,5,6,7,8,9,10$ & cytoplasm, nucleus, nuclear evelope, mitochondrion, vacuole & $\mathrm{R}$ & $x$ & 18 \\
\hline SNF4 & YGLII5W & S & $1,3,4,5,6,7,8,9,10$ & cytoplasm, nucleus, nuclear envelope, PM & & & 7 \\
\hline CNBI & YKLI90W & s & $1,3,4,5,7,9,10$ & calcineurin complex & & $x$ & 48 \\
\hline EOSI & YNL080C & S & $1,3,4,7$ & ER membrane & & $x$ & 4 \\
\hline SIS2 & YKR072C & $s$ & $1,3,5,10$ & cytoplasm, nucleus & & $x$ & 10 \\
\hline NUMI & YDRI50W & $\underline{\mathbf{s}}$ & $1,3,7,9$ & cell cortex, cellular bud tip, mitochondrion & & & 57 \\
\hline SWI4 & YERIIIC & s & $1,3,7,10$ & nucleus & $\mathrm{CW}$ & & 69 \\
\hline UBP6 & YFROIOW & S & $1,3,8,9,10$ & proteosome & & $x$ & 28 \\
\hline $\mathrm{MSCl}$ & YMLI28C & $\underline{\mathbf{s}}$ & $1,3,9,6$ & ER, mitochondrion & $\mathrm{R}$ & & 14 \\
\hline ARP6 & YLR085C & s & $10,1,2$ & SWRI complex, cytoplasm & $\mathrm{R}$ & & 149 \\
\hline CAF40 & YNL288W & $\underline{\mathrm{s}}$ & 2,10 & CCR4-NOT complex & $\mathrm{R}$ & & 8 \\
\hline NSTI & YNL09IW & s & 2,10 & cytoplasm & & $x$ & 2 \\
\hline PUBI & YNL0I6W & s & 2,10 & cytoplasm, nucleus, hnRNP complex & & $x$ & 5 \\
\hline $\mathrm{PIHI}$ & YHR034C & s & $2,3,8,10$ & cytoplasm, nucleus, snRNP complex & & & 2 \\
\hline HMTI & YBR034C & s & 2,410 & nucleus & & & 4 \\
\hline PML39 & YMLI07C & SL & $2,4,10$ & nuclear pore, ribosome & & & 4 \\
\hline HCRI & YLRI92C & $s$ & 2,8 & translation IF3 complex & $\mathrm{T}$ & $x$ & 5 \\
\hline PPQI & YPLI79W & $S$ & 2,8 & cytoplasm & & & 0 \\
\hline TMA23 & YMR269W & $\underline{s}$ & 2,8 & nucleolus, ribosome & & & 5 \\
\hline RRP6 & YOROOIW & SL & $2,8,10$ & nuclear exosome (RNase complex) & & & 16 \\
\hline SKYI & YMR216C & s & $2,3,4,8,10$ & cytoplasm & & & 5 \\
\hline STPI & YDR463W & s & $2,4,7,8,10$ & nucleus & & & 2 \\
\hline KNSI & YLL0I9C & SL & 3 & & & $x$ & 0 \\
\hline BIMI & YER0I6W & $s$ & $3,1,7$ & cytoplasm, microtubule, kinetochore, spindle pole body & & & 282 \\
\hline NBP2 & YDRI62C & s & 3,7 & cytoplasm, nucleus & $\mathrm{CW}, \mathrm{R}$ & $x$ & 49 \\
\hline PRBI & YEL060C & s & $3,8,9$ & vacuole & & $x$ & 3 \\
\hline SELI & YMLOI3W & $\underline{s}$ & $3,8,9$ & ubiquitin ligase complex, ER, mitochondrion & & & 3 \\
\hline TPS2 & YDR074W & $\underline{s}$ & $3,5,7,8,10$ & mitochondrion & & $x$ & 4 \\
\hline ITRI & YDR497C & s & $4,5,7,9$ & plasma membrane & & $x$ & 9 \\
\hline NEWI & YPL226W & s & $4,5,9,8$ & cytoplasm, mitochondrion & & & 8 \\
\hline$A Q R 2$ & YBR043C & s & 4,7 & plasma membrane & & & I \\
\hline GTRI & YMLI2IW & $s$ & 4,9 & cytoplasm, endosome, nucleus, vacuole & $\mathrm{T}, \mathrm{E}, \mathrm{R}$ & & 5 \\
\hline VAMIO & YOR068C & SL & 4,9 & vacuolar membrane & & & $\mathrm{II}$ \\
\hline SERI & YORI84W & s & 5 & cytoplasm & & & I \\
\hline SER2 & YGR208W & s & 5 & cytoplasm, nucleus & & & 5 \\
\hline GCR2 & YNLI99C & SL & $5,10,3$ & nucleus & $E$ & & 30 \\
\hline AROI & YDRI27W & SL & 5,6 & cytoplasm & $E$ & & 0 \\
\hline
\end{tabular}




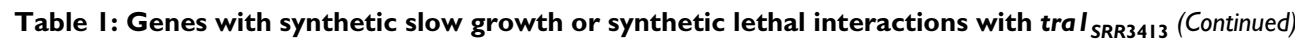

\begin{tabular}{|c|c|c|c|c|c|c|c|}
\hline$\overline{A R O 2}$ & YGLI48W & SL & 5,6 & cytoplasm & & & $T$ \\
\hline ETRI & YBR026C & $\underline{\mathbf{s}}$ & 5,6 & mitochondrion & & & 0 \\
\hline LIP2 & YLR239C & $s$ & 5,6 & mitochondrion & & & 7 \\
\hline LIP5 & YORI96C & $S$ & 5,6 & mitochondrion & & & 2 \\
\hline OARI & YKL055C & $s$ & 5,6 & mitochondrion & & & 0 \\
\hline ERG3 & YLR056W & $s$ & 5,9 & ER & & & 19 \\
\hline MDM34 & YGL219C & $\underline{\mathrm{S}}$ & 6 & mitochondrial outer membrane & $E, R$ & & 10 \\
\hline KGD2 & YDRI48C & $S$ & 6,5 & mitochondrion & & & 0 \\
\hline MDMIO & YALOIOC & $\underline{s}$ & 6,9 & $\begin{array}{l}\text { Mdm I0/Mdm I2/Mmm I complex, mitochondrial outer } \\
\text { membrane }\end{array}$ & $\mathrm{T}, \mathrm{E}$ & & 11 \\
\hline BEMI & YBR200W & $S$ & $7,3,1$ & bud neck & $E$ & & 33 \\
\hline BEM4 & YPLI6IC & $\underline{\mathbf{s}}$ & $7,3,1$ & cytoplasm, nucleus & $\mathrm{T}, \mathrm{E}$ & $x$ & 29 \\
\hline Smil & YGR229C & $\underline{\mathbf{s}}$ & $7,3,1$ & bud tip, nucleus & $\mathrm{T}, \mathrm{E}, \mathrm{CW}, \mathrm{R}$ & & 111 \\
\hline ROM2 & YLR37IW & $\overline{S L}$ & $7,3,9$ & bud tip & & $x$ & 16 \\
\hline CSFI & YLR087C & $\underline{\mathbf{s}}$ & $7,5,6$ & mitochondrion & $\mathrm{CW}$ & & 24 \\
\hline ECM30 & YLR436C & $\underline{\mathbf{s}}$ & 7,9 & cytoplasm & $\mathrm{CW}$ & & I \\
\hline KREI & YNL322C & $s$ & 7,9 & cell wall & & & 64 \\
\hline VIPI & YLR4IOW & $\underline{\mathrm{S}}$ & 7,9 & cytoplasm & & & 15 \\
\hline TPMI & YNL079C & $\bar{S}$ & $7,9,3$ & actin cable & $\mathrm{E}, \mathrm{CW}, \mathrm{R}$ & & 21 \\
\hline RPS27B & YHR02IC & $\mathrm{S}$ & 8 & ribosome & $\mathrm{T}$ & & I \\
\hline RPN4 & YDL020C & $\mathrm{S}$ & $8,10,1,3$ & nucleus, proteasome & $\mathrm{T}, \mathrm{E}$ & $x$ & 242 \\
\hline YDJI & YNL064C & $S$ & $8,9,6$ & cytosol, microsome & $\mathrm{R}$ & $x$ & 27 \\
\hline CCZI & YBRI3IW & $\mathrm{s}$ & 9 & late endosome, membrane & $E, R$ & $x$ & 6 \\
\hline MONI & YGLI24C & $s$ & 9 & cytosol, vacuolar membrane & & & 12 \\
\hline VAM3 & YORI06W & $s$ & 9 & vacuolar membrane & $\mathrm{R}$ & & 9 \\
\hline VAM7 & YGL2I $2 W$ & $s$ & 9 & vacuolar membrane & $\mathrm{T}, \mathrm{E}, \mathrm{CW}, \mathrm{R}$ & & 8 \\
\hline PIB2 & YGL023C & $\underline{\mathbf{s}}$ & $9,1,7$ & late endosome, mitochondrion & $\mathrm{R}$ & & 0 \\
\hline \multirow[t]{2}{*}{ GSGI } & YDRI08W & s & 9,3 & TRAPP complex & & $x$ & 11 \\
\hline & YDR049W & s & $9,3,8$ & cytoplasm, mitochondrion & $E, R$ & & \\
\hline MEHI & YKR007W & $S$ & $9,4,5$ & cytosol, vacuolar membrane & & $x$ & 2 \\
\hline PMRI & YGLI67C & $\mathrm{s}$ & $9,4,7$ & Golgi membrane & $\mathrm{E}$ & & 41 \\
\hline AUT7 & YBL078C & $s$ & 9,5 & autophagic vacuole, cytosol & & $x$ & 2 \\
\hline$C C W / 2$ & YLRIIOC & $s$ & 9,7 & cell wall & $\mathrm{CW}$ & & 13 \\
\hline COG5 & YNL05IW & $S$ & 9,7 & Golgi & & & 14 \\
\hline COG6 & YNL04IC & $\mathrm{S}$ & 9,7 & Golgi & & & 17 \\
\hline COG7 & YGL005C & $\mathrm{S}$ & 9,7 & Golgi & & & 12 \\
\hline COG8 & YML07IC & $\mathrm{S}$ & 9,7 & Golgi & & & 17 \\
\hline DID2 & YKR035W & s & 9,7 & cytoplasm, late endosome & & & 2 \\
\hline GYPI & YOR070C & $S$ & 9,7 & Golgi, mitochondrion & $\mathrm{R}$ & & 48 \\
\hline MNNIO & YDR245W & $\underline{\mathbf{s}}$ & 9,7 & $\alpha-1,6$-mannosyltransferase complex & $E, R, C W$ & & 19 \\
\hline MON2 & YNL297C & s & 9,7 & cytosol, endosome & $\mathrm{R}$ & & 40 \\
\hline $\mathrm{RICl}$ & YLR039C & $\mathrm{S}$ & 9,7 & Golgi, nucleus & $E$ & & 159 \\
\hline RUD3 & YOR216C & $s$ & 9,7 & Golgi & & & 26 \\
\hline SEC22 & YLR268W & $\underline{\mathbf{s}}$ & 9,7 & ER, Golgi & $\mathrm{CW}$ & & 44 \\
\hline TLG2 & YOLOI8C & s & 9,7 & early endosome, trans Golgi & $\mathrm{R}$ & & 12 \\
\hline VPSI & YKROOIC & $\mathrm{S}$ & 9,7 & cytoplasm, membrane fraction & & & 28 \\
\hline VPSI7 & YORI32W & $s$ & 9,7 & endosome, retromer complex & & & 11 \\
\hline VPS38 & YLR360W & s & 9,7 & Vps34 complex & $\mathrm{R}$ & & 12 \\
\hline VPS4I & YDR080W & s & 9,7 & HOPS complex, vacuolar membrane, endosome & $\mathrm{R}$ & & 7 \\
\hline VPS53 & YJL029C & SL & 9,7 & GARP complex, Golgi, cytoplasm & $\mathrm{T}, \mathrm{R}$ & & 10 \\
\hline YPT6 & YLR262C & $\underline{\mathbf{s}}$ & 9,7 & Golgi & $E, R$ & & 181 \\
\hline \multirow[t]{2}{*}{ YPT7 } & YML00IW & $s$ & 9,7 & vacuole, mitochondrion & $\mathrm{T}, \mathrm{R}$ & & 6 \\
\hline & YLRIIIW & s & 9,7 & & $\mathrm{CW}$ & & 0 \\
\hline GETI & YGL020C & $\underline{\mathrm{S}}$ & 9,8 & GET complex, ER, mitochondrion & $\mathrm{R}$ & $x$ & 284 \\
\hline SSEI & YPLI06C & $\underline{\mathrm{SL}}$ & 9,8 & cytoplasm & $\mathrm{T}$ & & 15 \\
\hline BTSI & YPL069C & $S$ & $9,5,6$ & mitochondrion & $\mathrm{CW}$ & & 16 \\
\hline UBP3 & YERI5IC & s & $9,7,10,1,3$ & cytoplasm & $\mathrm{R}$ & & 32 \\
\hline
\end{tabular}


Table I: Genes with synthetic slow growth or synthetic lethal interactions with tra SRR34I3 $_{\text {(Continued) }}$

\begin{tabular}{llll}
\hline YDLI80W & $s$ & vacuole & 0 \\
YEL033W & $\underline{s}$ & & T \\
YOR235W & $s$ & & 0
\end{tabular}

\footnotetext{
I Genes are placed according to related GO terms with relevant groupings separated by lines.

2 Phenotype of double mutants. SL, synthetic lethal; S, severe slow growth; s, slow growth (in SC media at $33.5^{\circ} \mathrm{C}$ ). For those underlined the phenotype is most easily detected on YPD at $30 \mathrm{C}$ as the single mutant shows reduced growth on SC media

${ }^{3}$ Gene ontology: (I) DNA replication/repair and chromosome stability, (2) RNA processing, (3) cell cycle/microtubule, (4) general transport, (5) metabolism, (6) mitochondria, (7) polarity/cell wall, (8) protein/ribosome biosynthesis, (9) secretion/protein trafficking, (10) transcription, (II) unknown

${ }^{4}$ Cellular compartments and/or components as indicated in the Saccharomyces Genome Database

${ }^{5}$ Relevant phenotypes of single mutants as described in the Saccharomyces Genome Database. E, sensitivity to ethanol; CW, sensitivity to calcofluor white; $T$, shortened telomeres; $R$, sensitivity to rapamycin

${ }^{6}$ Annotated in the Saccharomyces Genome Database as involved in stress response or autophagy

7 Number of previously identified SSL interactions in the Saccharomyces Genome Database
}

ric1 $0, y p t 60$ and swf1 0 . Three of these (ric1, ypt6 and gyp1) show synthetic interactions with tra $1_{S R R 3413}$ (Table $1)$. All encode key regulatory molecules in the processes of membrane sorting and protein trafficking [16], and with the exception of SWF1 are GTPases of the Ras-family or regulatory proteins of these molecules. Interestingly, ric1 was first identified as a temperature sensitive allele that affected transcription of both ribosomal protein genes and rRNA [17]. Also closely associated with this group was cnb1 0, which is SSL with $\operatorname{tra}_{S R R 3413}$ and encodes a $\mathrm{Ca}^{2+}$ / calmodulin dependent protein phosphatase required for cell cycle regulation, stress induced gene expression and cell wall synthesis. To gain additional confidence in the apparent association of $\operatorname{tra}_{S R R 3413}$ with the family of GTPases, the cluster analysis was repeated in the absence of these genes. In this case, $\operatorname{tra} 1_{S R R 3413}$ clustered with a group containing SAGA/SLIK and NuA4 components (not shown).

\section{Sorbitol partially suppresses defects due to tra I SRR34/3} SSL interactions with a number of genes (CCW12, CNB1, ECM30, KRE1, MNN10, ROM2, SMI1 and TOR1) that have functional links to cell wall organization and biogenesis was consistent with the calcofluor white and ethanol sensitivity of the $\operatorname{tra}_{S R R 3413}$ strain [9]. We thus investigated the extent to which the temperature sensitivity of the tra $1_{S R R 3413}$ strain results from cell wall destabilization by examining if it is suppressed by growth in media containing $1 \mathrm{M}$ sorbitol. As shown in Figure 2, sorbitol partially, but not completely, suppressed the temperature sensitive growth at $37^{\circ} \mathrm{C}$ of this strain (compare relative growth of $t r a 1_{S R R}$ and TRA1 in SC with sorbitol, lower panel, and without sorbitol, upper panel), indicating that defects in cell wall function contribute to but are not exclusively responsible for the temperature sensitivity. We also examined if some of the SSL interactions were largely due to cell wall instability. $m d m 340 \operatorname{tra}_{\text {SRR } 3413}$, swc3 0 $\operatorname{tra}_{\text {SRR3413 }}$, mon $20 \operatorname{tra}_{S R R 3413}$ and $\operatorname{cog} 50 \operatorname{tra}_{\text {SRR } 3413}$ were examined as representative of mitochondrial, chromosomal and membrane sorting groups. As shown in Figure
3 , growth inhibition of the $m d m 340$ tra $1_{S R R 3413}$ strain (at $33.5^{\circ} \mathrm{C}$ for this experiment in contrast to $37^{\circ} \mathrm{C}$ for Figure 2) was partially rescued by $1 \mathrm{M}$ sorbitol. Slight suppression was seen for the $\operatorname{cog} 50 \operatorname{tra} 1_{S R R 3413}$ strain, while growth of the swc3 $0 \operatorname{tra}_{\text {SRR } 3413}$ and mon $20 \operatorname{tra}_{\text {SRR } 3413}$ strains was relatively unchanged by sorbitol. The strain dependent differences in the ability of sorbitol to suppress SSL effects further establish that Tra1 has roles in multiple processes.

\section{Connection of TRAI to cellular stress}

We were intrigued by the finding that amongst the genes showing SSL interactions with $\operatorname{tra}_{\text {SRR } 3413}, 30$ are annotated to stress response or autophagy (see Table 1). This is an underestimate as, for example, Swi4 [18], Rps27b [19], Caf40 [20], Vps1 [21] and Stp1 [22] have been implicated in stress response but are not directly annotated as such. Some of the stress response genes include key signaling and regulatory molecules such as Tor1, Msk1, Cnb1, and Rom2; others have functions in protein turnover (Ubi4 and Rpn4), organization of the cytoskeleton (Tpm1 and Bem4) and DNA repair (Rad52, Ckb2, Doa1). To further examine the link between Tra1 and cellular stress response we tested the sensitivity of the $\operatorname{tra} 1_{S R R 3413}$ strain to rapamycin and to staurosporine. As shown in Figure 4, the tra $1_{S R R 3413}$ strain was partially sensitive to rapamycin, and to a lesser extent staurosporine. As staurosporine results in cell wall instability through its action on Protein Kinase C $[23,24]$, we also examined the $\operatorname{tra}_{\text {SRR3413 }}$ strain for sensitivity to the combination of calcofluor white and staurosporine. The tra1 $1_{S R R 3413}$ strain was extremely sensitive to calcofluor white in the presence of staurosporine, consistent with a role for Tra1 in events required for cell wall integrity.

\section{Relationship of tral SRR34I3 $_{3}$ to other mutations in SAGAI SLIK and NuA4 components}

Bruno et al. [25] have shown that deletion of the Ada2 homologue in C. albicans results in sensitivity to cell wall destabilizing agents. In addition, both SAGA/SLIK and 


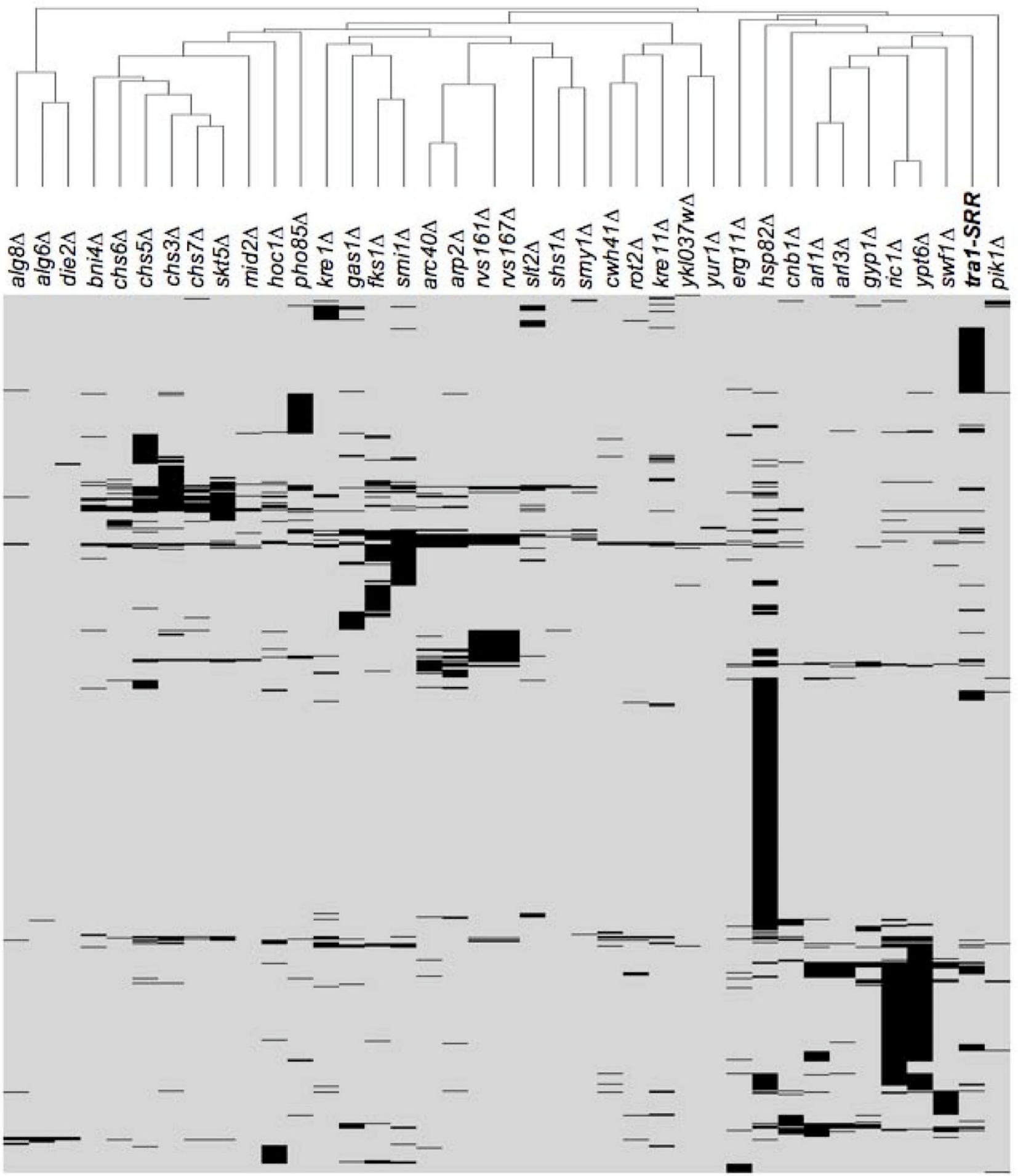

Figure I

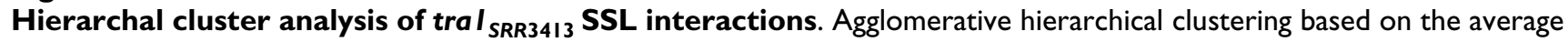
linkage of uncentered correlations using CLUSTER 3.0 software [50] was performed on the profile obtained with the tral ${ }_{S R R 3413}$ strain and the combined data sets of Tong et al. [II], Measday et al. [12], Reguly et al. [13], Pan et al. [14], Mitchell et al. [15] and including SSL interactions of additional SAGA/SLIK and NuA4 components as listed in the Saccharomyces Genome Database. Only the profiles clustering close to tra SRR3413 $_{3}$ are shown. 
NuA4 have been suggested to be involved in stress response based upon the transcription profiles of deletion strains [26,27]. As some of the genetic interactions and phenotypes of the $\operatorname{tra} 1_{S R R 3413}$ strain may result from a SAGA/SLIK or NuA4-dependent inability to induce stress response genes, we analyzed staurosporine, calcofluor white, calcofluor white plus staurosporine and rapamycin sensitivity in strains deleted for additional components of these complexes (Figure 5). The effect of $\operatorname{tra} 1_{S R R 3413}$ under each of these conditions is similar to, though slightly less severe than, that seen upon deletion of the ada genes (ada2, ngg1/ada3 and gcn5/ada4) of the SAGA/SLIK complexes. Interestingly, despite the fact that deletion of $s p t 7$ results in disruption of the complexes, spt7 0 results in less of an effect on rapamycin and calcofluor white than deletion of the ada genes, suggesting a potential role for an independent Ada complex [28]. This similarity between the ada genes and $\operatorname{rra}_{S R R 3413}$ is also consistent with our previous finding that the expression profile in the tra $1_{\text {SRR } 3413}$ strain most closely resembled deletion of ada2 [9]. Less similarity was seen in the phenotypes with NuA4 components though deletion of yafs and eaf7 did lead to reduced growth in calcofluor white plus staurosporine containing media and deletion of yafo resulted in a slight reduction of growth in media containing rapamycin.

\section{GFP-tagged Tral localizes to nucleus}

The requirement for an intact C-terminal FATC domain [1] has meant that Tra1 localization has not been tested in genome-wide screens. Localization of Tra1 to sites outside the nucleus potentially could account for the broad range of genetic interactions seen for the molecule. To examine cellular localization, we engineered an N-terminally GFPtagged allele of TRA1 that is functional as determined by plasmid shuffling assays (not shown). As shown in Figure 6, the pattern of GFP-Tra1 distribution was very similar to that of the SAGA/SLIK component Ngg1/Ada3 and coincided with DAPI staining within the nucleus (Figure 6). A low level of fluorescence was apparent throughout the cell, making it difficult to fully exclude that lesser amounts exist in other compartments; however, GFP-Tra1 was not in foci other than the nucleus.

\section{Discussion}

Identification of the SSL interactions for the $\operatorname{tra} 1_{S R R 3413}$ allele has provided insights into the function of this molecule. The genes identified link Tra1 to many cellular functions including membrane sorting/protein trafficking, cell wall biogenesis/function, RNA processing, gene expression and mitochondrial function. The number of genetic interactions identified for $\operatorname{tra} 1_{S R R 3413}$ is likely due to its function in two key cellular regulatory complexes, SAGA/SLIK and NuA4.

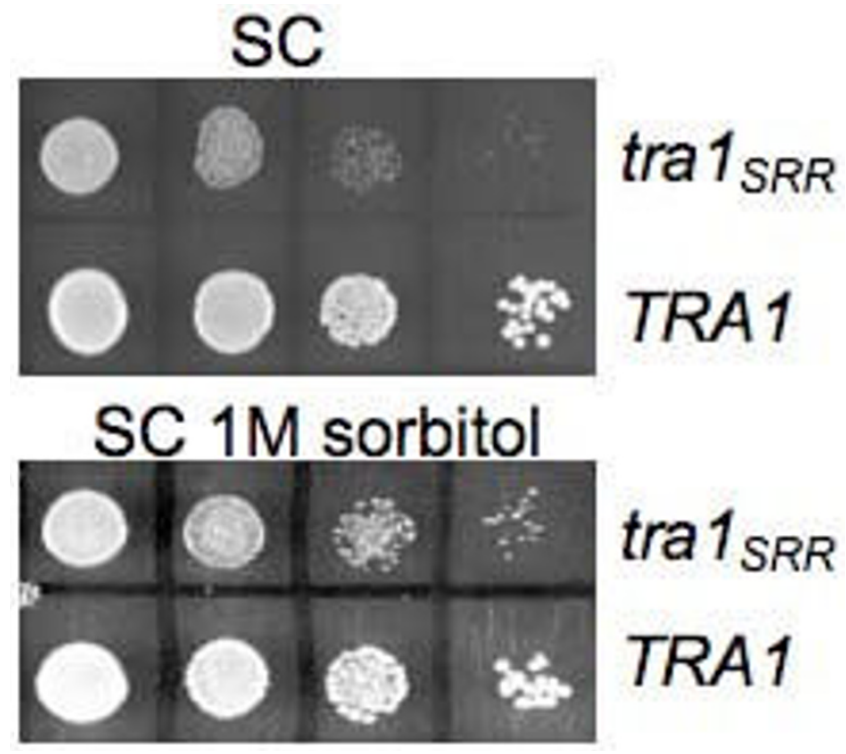

Figure 2

Sorbitol partially suppresses slow growth at $37^{\circ} \mathrm{C}$ due to tra I SRR3413. Yeast strains CY2222 (tral $_{\text {SRR34I3) and }}$ BY7092 (TRA I) were grown overnight to saturation in YPD at $30^{\circ} \mathrm{C}$. Cells were diluted to approximately 1000 cells per $\mu \mathrm{l}$ and $10 \mu \mathrm{l}$ of 10 -fold serial dilutions spotted on synthetic complete media containing $2 \%$ glucose without (SC) or with I.0 M sorbitol. Cells were grown for 4 days at $37^{\circ} \mathrm{C}$.

The finding that the SSL profile for $\operatorname{tra}_{\text {SRR } 3413}$ does not share greater similarity with mutations of other SAGA/ SLIK and NuA4 components agrees with our previous observations that these strains differ in their transcription profiles, effects on telomere length and sensitivity to the DNA damaging agent methylmethanesulfonate [9]. These differences may arise from the integrative effects of disturbing both complexes and/or the possibility that Tra 1 has a unique function. While differences are apparent, we do note that if the cluster analysis is performed in the absence of the $\operatorname{arl} 10, \operatorname{arl} 30, \operatorname{syp} 10, \operatorname{ric} 10, y p t 60$ and swf1 0 group, the SSL profile for $\operatorname{tra} 1_{S R R 3413}$ clusters most closely with SAGA/SLIK and NuA4 components (not shown). In addition, as seen by the common sensitivity to ethanol and calcofluor white plus staurosporine, several of the $\operatorname{tra} 1_{\text {SRR } 3413}$ phenotypes are similar to deletions of the ada genes.

\section{Nuclear function}

SAGA/SLIK and NuA4 are nuclear complexes and indeed we have found Tra1 to be predominately, if not exclusively, localized in the nucleus. As an essential component of two histone-modifying complexes, it is not surprising that approximately 40 of the SSL interactions are with genes annotated principally as having roles in nuclear 


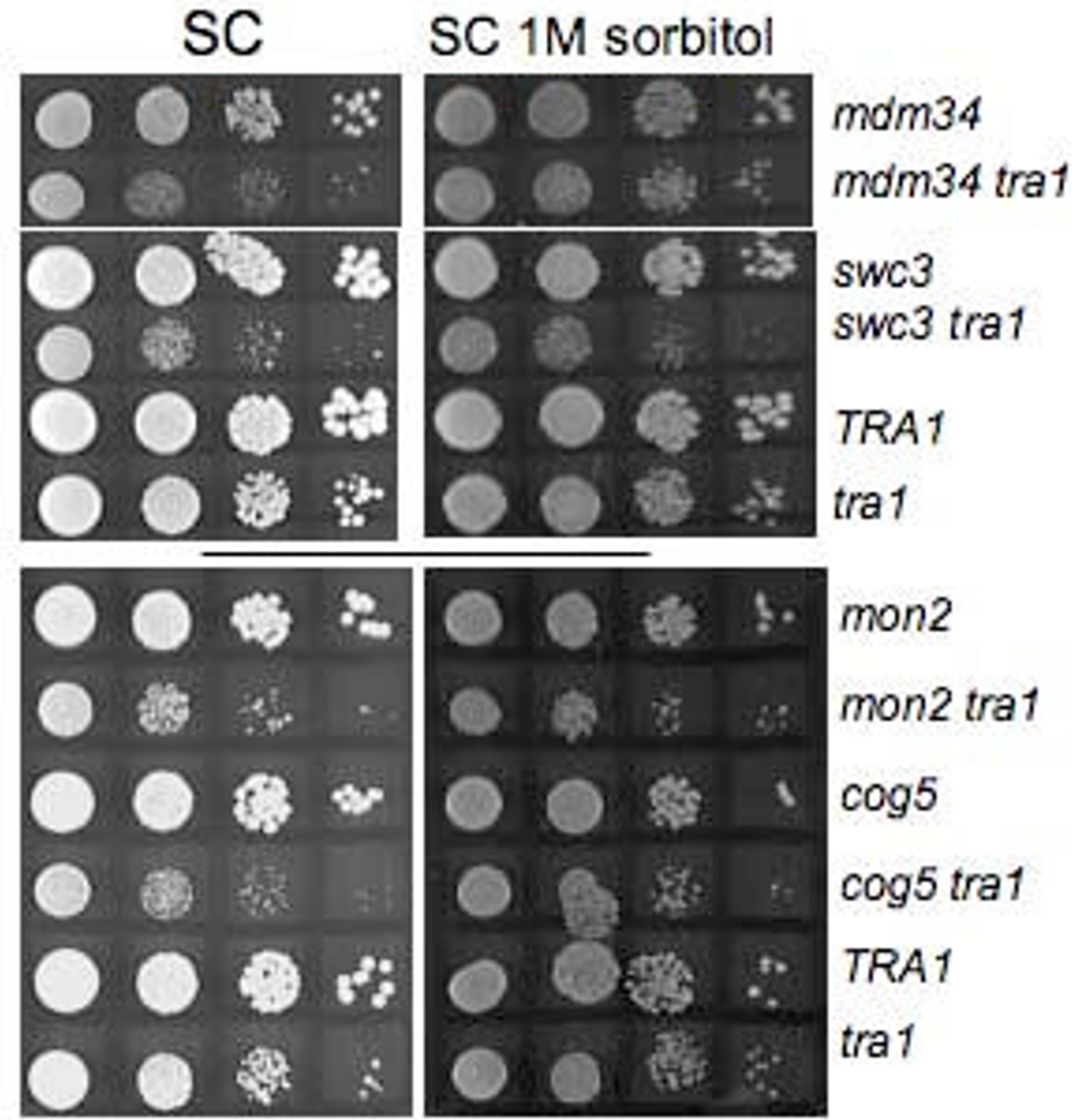

Figure 3

Growth of tra $I_{S R R 3413}$ double mutant strains in sorbitol. Strains containing the indicated single disruptions $(m d m 34$,

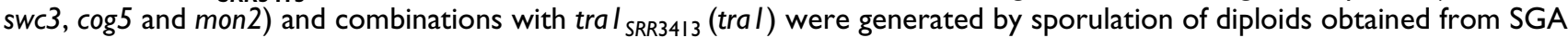
analysis. These strains plus CY2222 (tra $I_{S R R 34 I 3}$ ) and BY7092 (TRAI) were grown overnight to saturation in YPD at $30^{\circ} \mathrm{C}$. Cells were diluted to approximately 2000 cells per $\mu \mathrm{l}$ and $5 \mu \mathrm{l}$ of 10 -fold serial dilutions spotted on synthetic complete media containing $2 \%$ glucose without (SC) or with I.0 M sorbitol. Cells were grown for 3 days (upper grouping) or 2 days (lower grouping) at $33.5^{\circ} \mathrm{C}$. 

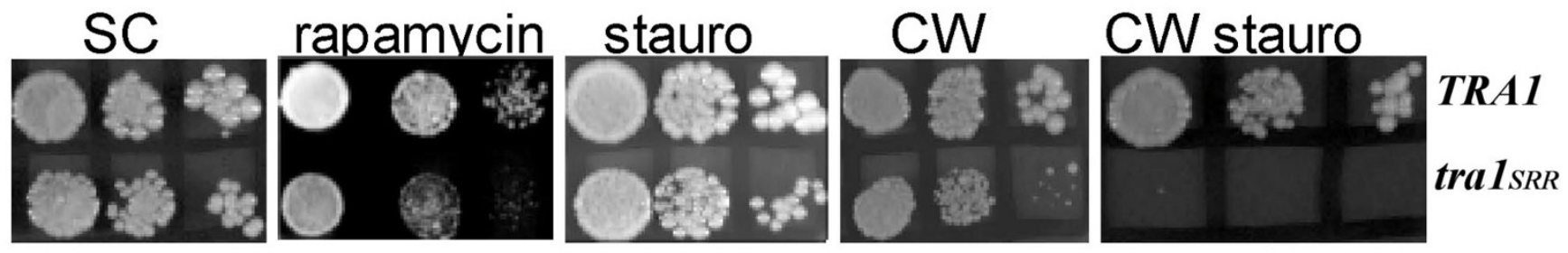

Figure 4

Growth of the tra $I_{S R R 3413}$ strain under conditions of cellular stress. Yeast strains BY7092 (TRAI) and CY2222 (tral SRR3413 ) were grown overnight to saturation in YPD at $30^{\circ} \mathrm{C} .5 \mu \mathrm{l}$ of 10 -fold serial dilutions were spotted onto synthetic complete media containing $2 \%$ glucose (SC) or with the addition of $2 \mathrm{nM}$ rapamycin, $2 \mu \mathrm{g} / \mathrm{ml}$ staurosporine (stauro), $7.5 \mu \mathrm{g} / \mathrm{ml}$ calcofluor white (CW), or $2 \mu \mathrm{g} / \mathrm{ml}$ staurosporine plus $7.5 \mu \mathrm{g} / \mathrm{ml}$ calcofluor white (CW stauro). Cells were grown for 3 days on $\mathrm{SC}$ and 5 days on selective plates, at $30^{\circ} \mathrm{C}$.

function or gene expression. Some of these genes (for example: pub1, pml39 and sky1) are involved with RNA processing, export or stability perhaps reflecting a role for the SAGA complex at the nuclear pore [29]. Another clear subset of SSL interactions includes genes of the SWR1 complex and $h t z 1$. In this case the relationship with $\mathrm{tra}_{\text {SRR } 3413}$ almost certainly reflects their combined importance in determining chromatin structure and their resulting influence on transcription and/or DNA repair. Supporting this argument, SSL interactions have been observed between many components of SAGA and NuA4 with $h t z 1$ and SWR1 complex genes [30]. Similarly the interaction of $\operatorname{tra1}_{S R R 3413}$ with rad52 may relate to the function of the NuA4 complex in DNA repair.

\section{Membrane processes}

The association of SAGA/SLIK and NuA4 components with membrane processes has been noted previously. Gen5 and Spt20 are required for the unfolded protein response [31,32]. A strain with deletion of eaf1/vid21 (Vacuolar Import Degradation) was identified in a screen for defects in sorting of carboxypeptidase $Y$ to the vacuole [33] and results in sensitivity to ethanol [34]. In addition, Eaf1 interacts with Vac8, which is required for several aspects of vacuolar function [35]. eaf3, eaf5, eaf7, eaf1/

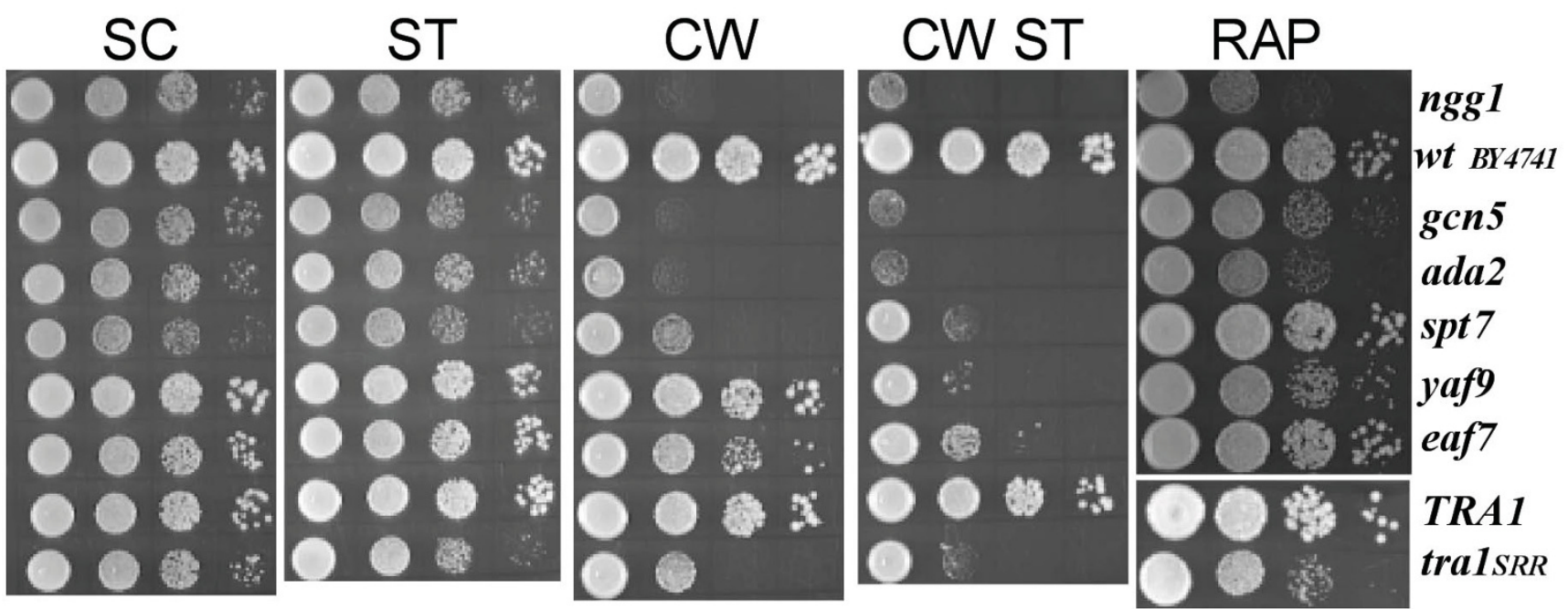

\section{Figure 5}

Phenotypic comparison of tra SRR34I3 $_{3}$ with deletions of SAGA/SLIK and NuA4 components. Yeast strains BY3534 (ngg/ 0), BY474I (wild-type background for deletion strains), BY7285 (gcn5 0), BY4282 (ada 0), BY328I (spt7 0), BY4240

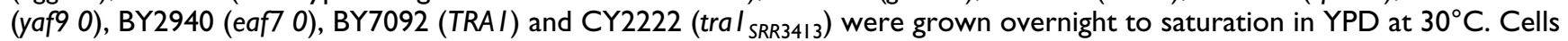
were diluted to approximately 2000 cells per $\mu \mathrm{l}$ and $5 \mu \mathrm{l}$ of 10 -fold serial dilutions spotted on synthetic complete media containing $2 \%$ glucose (SC), with $2 \mu \mathrm{g} / \mathrm{ml}$ staurosporine (ST), $7.5 \mu \mathrm{g} / \mathrm{ml}$ calcofluor white (CW), or $2 \mu \mathrm{g} / \mathrm{ml}$ staurosporine plus 7.5 $\mu \mathrm{g} / \mathrm{ml}$ calcofluor white (CW ST) or YPD with $2 \mathrm{nM}$ rapamycin (RAP). SC and ST were grown for 2 days at $30^{\circ} \mathrm{C}, \mathrm{CW}$ and $\mathrm{CW}$ ST for 3 days, and RAP for 4 days. For the rapamycin image, TRAI and tra $I_{S R R}$ were grown on a separate plate. 


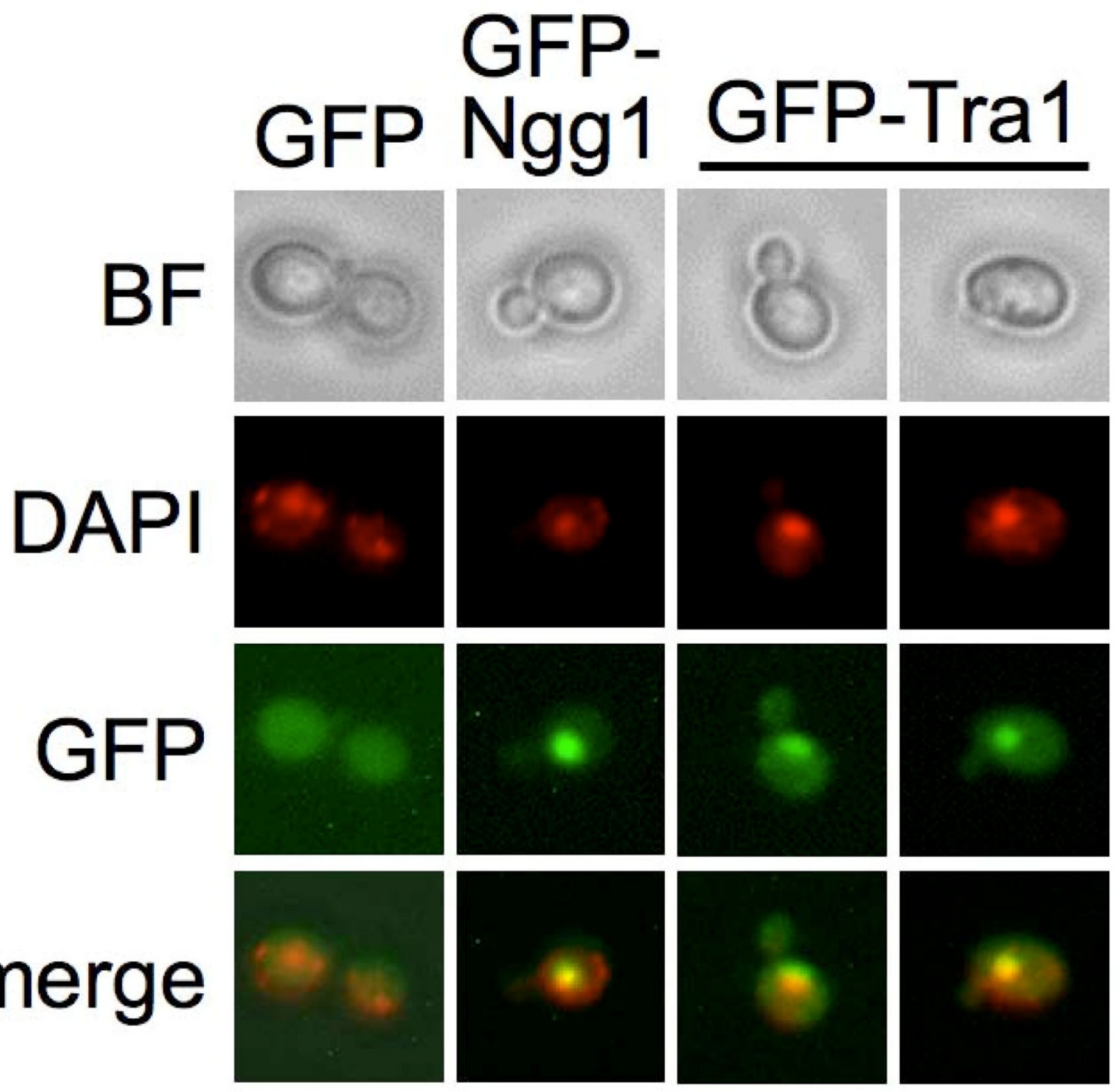

\section{Figure 6}

GFP-Tral is found predominately in the nucleus. Yeast strain BY474I, expressing either GFP, GFP-NggI or GFP-Tral from a URA3-centromeric plasmid was grown in synthetic complete media, stained with DAPI and examined by fluorescence microscopy. BF, bright field.

vid21 and yaf9 were identified as Opi mutants that result in overproduction of inositol, though not through direct repression of INO1 [36]. Mitchell et al. [15] have observed SSL interactions of nonessential NuA4 components with proteins involved in membrane sorting/protein trafficking. They find that deletion the NuA4 component genes leads to defects in vacuolar morphology and similar to what we suggest for the phenotypic effects of $\operatorname{tra}_{\text {SRR } 3413}$ predict that the vacuolar defects arise from changes in gene expression.

\section{Mitochondrial function}

Fifteen genes annotated to have links to mitochondrial function were identified in the screen. This may relate to the possible involvement of the SLIK complex in the retrograde response pathway [37]. Interestingly this pathway 
Table 2: Stress related genes down regulated in a tra $I_{S R R 3413}$ background.

\begin{tabular}{lcl}
\hline Gene & Fold-decrease & Description \\
\hline AAD4 & 1 I & Putative aryl-alcohol dehydrogenase. Involved in oxidative stress response. \\
TSA2 & 6.5 & Stress induced thioredoxin peroxidase. \\
CCSI & 5.5 & Copper chaperone for superoxide dismutase Sod I. Involved in oxidative stress protection. \\
AAD6 & 4.4 & Putative aryl-alcohol dehydrogenase. Involved in oxidative stress response. \\
GPX2 & 3.6 & Phospholipid hydroperoxide glutathione peroxidase. Protects cells from peroxides. \\
SSA4 & 3.3 & Heat shock protein that is highly induced upon stress. Role in SRP-dependent cotranslational protein-membrane \\
& & targeting. \\
GRX2 & 3.1 & Glutaredoxin, thioltransferase, glutathione-dependent disulfide oxidoreductase. Maintains redox state of target \\
& & proteins. \\
RHR2 & 3.0 & DL-glycerol-3-phosphatase. Induced by anaerobic and osmotic stress. \\
ALD2 & 2.4 & Aldehyde dehydrogenase. Stress induced. \\
TRX2 & 2.4 & Thioredoxin isoenzyme. Protects cells against oxidative stress. \\
GRE2 & 2.4 & 3-methylbutanal reductase and methylglyoxal reductase. Stress induced. \\
SRXI & 2.4 & Sulfiredoxin. Contributes to oxidative stress resistance. \\
ALD3 & 2.3 & Cytoplasmic aldehyde dehydrogenase. Stress induced. \\
LSPI & 2.3 & Component of eisosomes. Null mutants show activation of Pkclp/YpkIp stress pathways. \\
PST2 & 2.2 & Similarity to flavodoxin-like proteins. Induced by oxidative stress. \\
CMKI & 2.2 & Calmodulin-dependent protein kinase. May play a role in stress response. \\
DAKI & 2.0 & Dihydroxyacetone kinase. Involved in stress adaptation. \\
\hline
\end{tabular}

I Decrease in gene expression from microarray analysis [9], tra SRR34I3 versus TRAI

2 Modified from the Saccharomyces Genome Database

links mitochondrial metabolism with stress response, signaling the expression of genes that provide required biosynthetic precursors during mitochondrial dysfunction, which results in the loss of tricarboxylic acid cycle activity [38].

\section{Stress response}

Included in the $\operatorname{tra}_{S R R 3413}$ SSL genes are greater than 30 related to cellular stress or stress response. Genetic interactions for $\operatorname{tra}_{\text {SRR } 3413}$ with molecules related to cellular stress is consistent with the transcription profiles of strains containing deletions of SAGA/SLIK and NuA4 components $[26,27]$ as well as the calcofluor white, ethanol, rapamycin and temperature sensitivity of the $\operatorname{tra} 1_{S R R 3413}$ strain. An aspect of the involvement of Tra1 in stress likely includes a role in the cell wall integrity response pathway as indicated by the calcofluor white sensitivity and interactions of the $\operatorname{tra}_{S R R 3413}$ SSL profile with molecules required for membrane sorting/protein trafficking and cell wall components (for example, Kre1 and Ccw12). The processes identified with Tra 1 in many ways resemble those seen with Tor1, which as well as its initially defined role in integrating nutrient status with growth, has been genetically and functionally linked to membrane sorting/ protein trafficking, cytoskeletal events, microautophagy and to cell well integrity [39-43].

The simplest interpretation of a possible link between Tra1 and stress is to suggest that Tra1 is involved in the expression of stress response genes or genes whose lack of expression results in stress. Consistent with this, in YPD media seventeen genes with an annotation or description indicative of an involvement in stress response have decreased expression of two-fold or greater in a $\mathrm{tra}_{\text {SRR }}{ }_{\text {SR13 }}$ background ([9], Table 2). Many of these genes function in the response to oxidative stress but their exact role in determining phenotype is likely complex given that the tra $_{S R R 3413}$ strain is not sensitive to the oxidizing agent tert-butylhydroperoxide and genes typically elevated in response to stress are not found induced in the $\operatorname{tra}_{\text {SRR } 3413}$ strain.

We previously demonstrated that $\operatorname{tra}_{S R R 3413}$ results in a generation dependent telomere shortening that is not characteristic of other SAGA/SLIK or NuA4 components. Fifteen of the genes with SSL interactions with $\operatorname{tra}_{S R R 3413}$ also show telomere shortening [44]. In many cases direct telomeric functions for these molecules have not been described but like $\operatorname{tra}_{\text {SRR } 3413}$, they display slow growth in response to ethanol, calcofluor white or rapamycin. This suggests the possibility that shortened telomeres in the tra $1_{S R R 3413}$ strain is the result of a similar indirect mechanism rather than direct action at the telomere.

\section{Conclusion}

Through the identification of synthetic sick/lethal interactions with $\operatorname{tra}_{S R R 3413}$ we have demonstrated a genetic association of Tra1 not only with nuclear processes but also with membrane events and mitochondrial function. The identity of the SSL genes also connects Tra1 with cellular stress, a result confirmed by the sensitivity of the $\mathrm{tra}_{S R R 3413}$ strain to a variety of conditions that result in a stress response. The transcription profile and SSL interactions indicate that the functions of Tra1 can not simply be 
ascribed individually to either SAGA/SLIK or NuA4 complexes. However, the finding that many patterns of the $\mathrm{tra1}_{\text {SRR } 3413}$ phenotype resemble those seen with deletions of the Ada components of the SAGA/SLIK complex points toward a role for the PI3K domain of Tra1 in regulating the activity of the Ada molecules.

\section{Methods}

\section{Yeast strains and growth}

Yeast strains BY3534 (ngg1 0), BY7285 (gcn5 0), BY4282 (ada 0), BY3281 (spt7 0), BY4240 (yaf9 0), BY2940 (eaf7 0) are derivatives of BY4741 (MATa his3 0 , leu2 0 met1 0 ura3 $0 ;[45])$ and were purchased from Open Biosystems. Yeast strain CY2222 is a derivative of BY7092 (MAT can1 ::STE2pr-SpHIS5 lyp1 his3 1 leu2 0 ura3 0 met10 LYS2+) that has been gene replaced with $\operatorname{tra} 1_{S R R 3413}$ and selected for through the placement of Tn10LUK at the downstream BstBI site. To ensure that this integration did not hamper expression of YHR100C, a 2035 base pair EcoRI-HindIII fragment encompassing this gene was integrated after cloning into the LEU2 integrating vector YIplac128 [46] and digestion with MscI. Strains containing disruptions of individual genes and double mutants with $\operatorname{tra}_{S R R 3413}$ were obtained by tetrad dissection of diploids generated from the SGA analysis. Strains were spotted in ten-fold serial dilutions on synthetic complete media containing $2 \mathrm{nM}$ rapamycin (LC Laboratories, Woburn Ma), $7.5 \mu \mathrm{g} / \mathrm{ml}$ calcofluor white (Sigma-Aldrich Canada, Oakville Ontario), $2 \mu \mathrm{g} / \mathrm{ml}$ staurosporine (LC Laboratories), calcofluor white plus staurosporine, or 1.0 $\mathrm{M}$ sorbitol. Growth was also compared on synthetic complete media containing $1 \%$ potassium acetate and $0.05 \%$ glucose as the carbon source.

\section{GFP fusion protein and microscopy}

A URA3 centromeric plasmid that allowed expression of GFP fusions was engineered by inserting a BamHI-NotI fragment of the PCR product synthesized using oligonucleotides 5'-ATGCGGATCCACAATGGTGAGCAAGGGCGAGG-3 and 5'TTTTCCTTTTCCGGCCGCCTTGTACAGCTCGTCCATG-3' as primers and pEGFP-N1 (Clontech Laboratories, Inc.) as template to replace the tags of YCpDed-TAP-Flag [9]. TRA1 and NGG1 were inserted into this vector as NotI-SstI fragments from YCpDed-TAP-Flag-TRA1 (9) and YCpDed-myc-NGG1 [47], respectively. Fluorescence microscopy was performed as described by Brachat et al. [48] with minor modification. Yeast expressing GFP-tagged proteins were grown in SC media lacking uracil at $30^{\circ} \mathrm{C}$. At $\mathrm{A}_{600} \sim 0.8$, 4',6-diamidino-2-phenylindole (DAPI) was added to a final concentration of $5 \mu \mathrm{g} / \mathrm{ml}$ and the cells incubated at $30^{\circ} \mathrm{C}$ for an additional $1-2 \mathrm{hr}$. Cells from 1 $\mathrm{mL}$ of the culture were pelleted, resuspended in $100 \mu \mathrm{LSC}$ media, immobilized between a microscope slide and cover slip in SC media containing $0.7 \%$ agarose and observed using a Zeiss Axiovert 25 fluorescent microscope under $400 \times$ magnification. Images were captured, autoequalized, colorized and merged using Northern Elite software (Empix Imaging, Inc.).

\section{Systematic genetic-array analysis}

SGA analysis with yeast strain CY2222 was performed as described by Tong and Boone [49]. Each strain was pinned in quadruplicate with strains analyzed on synthetic media at $26^{\circ} \mathrm{C}, 34^{\circ} \mathrm{C}$ and $36^{\circ} \mathrm{C}$. Diploids of those strains showing slow growth at all temperatures were sporulated and subjected to tetrad dissection on YPD plates. When viable, the growth of single and double disruptions of the relevant gene were compared to CY2222 on YPD plates at $30^{\circ} \mathrm{C}$ and synthetic complete plates at $33.5^{\circ} \mathrm{C}$. Agglomerative hierarchical clustering based on the average linkage of uncentered correlations using CLUSTER 3.0 software [50] was performed on the profile obtained with the data sets of Tong et al. [11], Measday et al. [12], Reguly et al. [13], Pan et al. [14] and Mitchell et al. [15], as compiled by Mitchell et al. [15]. SSL interactions, as listed in the Saccharomyces Genome Database (March 2008), of additional components of SAGA/SLIK and NuA4 complexes were also included in the analysis.

\section{Authors' contributions}

SMTH carried out microscopy, data analysis and co-wrote the manuscript with CJB. JG performed the SGA analysis under the supervision of BA. CJB performed the analysis of individual strains. All authors have read and approved the final manuscript.

\section{Acknowledgements}

We would like to thank Irina Mutiu, Megan Davey and David Edgell for comments on this manuscript, David Litchfield for use of microscope facilities, Julie Genereaux for technical assistance and Esther Loney for constructing the GFP molecule. This work was supported by a Canadian Institutes of Health Research grant to CB. SH is supported by Schulich Graduate and Ontario Graduate Scholarships.

\section{References}

I. Bosotti R, Isacchi A, Sonnhammer EL: FAT: a novel domain in PIK-related kinases. Trends Biochem Sci 2000, 25:225-227.

2. Saleh A, Schieltz D, Ting N, McMahon SB, Litchfield DW, Yates JR 3rd, Lees-Miller SP, Cole MD, Brandl CJ: Tral is a component of the yeast Ada-Spt transcriptional regulatory complexes. J Biol Chem 1998, 273:26559-26565.

3. Grant PA, Schieltz D, Pray-Grant MG, Yates JR 3rd, Workman JL: The ATM-related cofactor Tral is a component of the purified SAGA complex. Mol Cell I 998, 2:863-867.

4. Allard S, Utley RT, Savard J, Clarke A, Grant P, Brandl C), Pillus L, JWorkman JL, Côté J: NuA4, an essential transcription adaptor/ histone $\mathrm{H} 4$ acetyltransferase complex containing Esalp and the ATM-related cofactor Tra I p. EMBO J 1999, I 8:5 I08-5II9.

5. Brown CE, Howe L, Sousa K, Alley SC, Carrozza MJ, Tan S, Workman JL: Recruitment of HAT complexes by direct activator interactions with the ATM-related Tral subunit. Science 200I, 292:2333-2337.

6. Bhaumik SR, Raha T, Aiello DP, Green MR: In vivo target of a transcriptional activator revealed by fluorescence resonance energy transfer. Genes Dev 2004, I 8:333-343. 
7. Fishburn J, Mohibullah N, Hahn S: Function of a eukaryotic transcription activator during the transcription cycle. Mol Cell 2005, I 8:369-378.

8. Reeves WM, Hahn S: Targets of the Gal4 transcription activator in functional transcription complexes. Mol Cell Biol 2005, 25:9092-9102.

9. Mutiu Al, Hoke SMT, Genereaux J, Hannam C, MacKenzie, JobinRobitaille O, Guzzo J, Côté J, Andrews B, Haniford DB, Brandl C]: Structure/function analysis of the phosphatidylinositol-3. kinase domain of yeast Tral. Genetics 2007, I77:| 5 I- I66.

10. Mizuguchi G, Shen X, Landry J, Wu WH, Sen S, Wu C: ATP-driven exchange of histone H2AZ variant catalyzed by SWRI chromatin remodeling complex. Science 2004, 303:343-348.

II. Tong AH, Lesage G, Bader GD, Ding H, Xu H, Xin X, Young J, Berriz GF, Brost RL, Chang M, Chen Y, Cheng X, Chua G, Friesen H, Goldberg DS, Haynes J, Humphries C, He G, Krogan N, Li Z, Levinson JN, Lu H, Menard P, Munyana C, Parsons AB, Ryan O, Tonikian R, Roberts T, Sdicu AM, Shapiro J, Sheikh B, Suter B, Wong SL, Zhang LV, Zhu H, Burg CG, Munro S, Sander C, Rine J, Greenblatt J, Peter M, Bretscher A, Bell G, Roth FP, Brown GW, Andrews B, Bussey H, Boone C: Global mapping of the yeast genetic interaction network. Science 2004, 303:808-8I3.

12. Measday V, Baetz K, Guzzo J, Yuen K, Kwok T, Sheikh B, Ding H, Ueta R, Hoac T, Cheng B, Pot I, Tong A, Yamaguchi-Iwai Y, Boone C, Hieter P, Andrews B: Systematic yeast synthetic lethal and synthetic dosage lethal screens identify genes required for chromosome segregation. Proc Natl Acad Sci USA 2005, I02:13956-1396|.

13. Reguly T, Breitkreutz A, Boucher L, Breitkreutz BJ, Hon GC, Myers CL, Parsons A, Friesen H, Oughtred R, Tong A, Stark C, Ho Y, Botstein D, Andrews B, Boone C, Troyanskya OG, Ideker T, Dolinski K, Batada NN, Tyers M: Comprehensive curation and analysis of global interaction networks in Saccharomyces cerevisiae. J Biol 2006, 5: II.

14. Pan X, Yuan DS, Wang X, Bader JS, Boeke JD: A DNA integrity network in the yeast Saccharomyces cerevisiae. Cell 2006 , I0:1069-|08|.

I5. Mitchell L, Lambert JP, Gerdes M, Al-Madhoun AS, Skerjanc IS, Figeys $D$, Baetz K: Functional dissection of the NuA4 histone acetyltransferase reveals its role as a genetic hub and that Eafl is essential for complex integrity. Mol Cell Biol 2008, 7:2244-2256.

16. Segev N: Ypt and Rab GTPases: insight into functions through novel interactions. Curr Opin Cell Biol 200I, I 3:500-5 I I.

17. Mizuta K, Park JS, Sugiyama M, Nishiyama M, Warner JR: RICI, a novel gene required for ribosome synthesis in Saccharomyces cerevisiae. Gene 1997, I87:I7I-I78.

18. Baetz K, Moffat J, Haynes J, Chang M, Andrews B: Transcriptional coregulation by the cell integrity mitogen-activated protein kinase SIt2 and the cell cycle regulator Swi4. Mol Cell Biol 200I, 21:6515-6528.

19. Uesono $\mathrm{Y}$, Toh-e A: Transient inhibition of translation initiation by osmotic stress. J Biol Chem 200I, 277:I3848-I3855.

20. Lenssen E, Azzouz N, Michel A, Landrieux E, Collart MA: The Ccr4Not Complex Regulates Skn7 through Srb I 0 Kinase. Eukaryot Cell 2007, 6:225I-2259.

21. Rand JD, Grant CM: The thioredoxin system protects ribosomes against stress-induced aggregation. Mol Biol Cell 2006 , | 7:387-40|.

22. Andreasson C, Ljungdahl PO: Receptor-mediated endoproteolytic activation of two transcription factors in yeast. Genes Dev 2002, 16:3158-3172.

23. Yoshida S, Ikeda E, Uno I, Mitsuzawa $\mathrm{H}$ : Characterization of a staurosporine- and temperature-sensitive mutant, stt $l$, of Saccharomyces cerevisiae. Mol Gen Genet 1992, 23 I:337-344.

24. Helliwell SB, Howald I, Barbet N, Hall MN: TOR2 is part of two related signaling pathways coordinating cell growth in Saccharomyces cerevisiae. Genetics 1998, I48:99-II2.

25. Bruno VM, Kalachikov S, Subaran R, Nobile CJ, Kyratsous C, Mitchell AP: Control of the $C$. albicans cell wall damage response by transcriptional regulator Cas5. PLoS Pathog 2006, 2:e21.

26. Huisinga KL, Pugh BF: A genome-wide housekeeping role for TFIID and a highly regulated stress-related role for SAGA in Saccharomyces cerevisiae. Mol Cell I 3:573-585.

27. Lindstrom KC, Vary JC Jr, Parthun MR, Delrow J, Tsukiyama T: Isw I functions in parallel with the NuA4 and SwrI complexes in stress-induced gene repression. Mol Cell Biol 2006, 26:6117-6129.

28. Saleh A, Lang V, Cook R, Brandl C): Identification of native complexes containing the yeast coactivator/repressor proteins Ngg I/Ada3 and Ada2. J Biol Chem 1997, 272:557/ -5578.

29. Rodriguez-Navarro S, Fischer T, Luo MJ, Antunez O, Brettschneider S, Lechner J, Perez-Ortin JE, Reed R, Hurt E: Sus I, a functional component of the SAGA histone acetylase complex and the nuclear pore-associated mRNA export machinery. Cell 2004, I | 6:75-86.

30. Collins SR, Miller KM, Maas NL, Roguev A, Fillingham J, Chu CS, Schuldiner M, Gebbia M, Recht J, Shales M, Ding H, Xu H, Han J, Ingvarsdottir K, Cheng B, Andrews B, Boone C, Berger SL, Hieter P Zhang Z, Brown GW, Ingles C], Emili A, Allis CD, Toczyski DP, Weissman JS, Greenblatt JF, Krogan NJ: Functional dissection of protein complexes involved in yeast chromosome biology using a genetic interaction map. Nature 2007, 446:806-8I0.

31. Welihinda AA, Tirasophon W, Green SR, Kaufman RJ: Gene induction in response to unfolded protein in the endoplasmic reticulum is mediated through Ire Ip kinase interaction with a transcriptional coactivator complex containing Ada5p. Proc Natl Acad Sci USA 1997, 94:4289-4294

32. Welihinda AA, Tirasophon W, Kaufman RJ: The transcriptional co-activator ADA5 is required for HACI mRNA processing in vivo. J Biol Chem 2000, 275:3377-338I.

33. Bonangelino C], Chavez EM, Bonifacino JS: Genomic screen for vacuolar protein sorting genes in Saccharomyces cerevisiae. Mol Biol Cell 2002, I3:2486-250I.

34. Fujita K, Matsuyama A, Kobayashi $Y$, Iwahashi $\mathrm{H}$ : The genome-wide screening of yeast deletion mutants to identify the genes required for tolerance to ethanol and other alcohols. FEMS Yeast Res 2006, 6:744-750.

35. Tang F, Peng Y, Nau JJ, Kauffman EJ, Weisman LS: Vac8p, an armadillo repeat protein, coordinates vacuole inheritance with multiple vacuolar processes. Traffic 2006, 7:|368-I377.

36. Hancock LC, Behta RP, Lopes JM: Genomic analysis of the Opiphenotype. Genetics 2006, I 73:621-634.

37. Pray-Grant MG, Schieltz D, McMahon SJ, Wood JM, Kennedy EL, Cook RG, Workman JL, Grant PA: The novel SLIK histone acetyltransferase complex functions in the yeast retrograde response pathway. Mol Cell Biol 2002, 22:8774-8786.

38. Jazwinski SM: The retrograde response links metabolism with stress responses, chromatin-dependent gene activation, and genome stability in yeast aging. Gene 2005, 34:22-27.

39. Cutler NS, Pan X, Heitman J, Cardenas ME: The Tor signal transduction cascade controls cellular differentiation in response to nutrients. Mol Cell Biol 200 I, I 2(I 2):4I03-4II3.

40. Araki T, Uesono Y, Oguchi T, Toh-e A: LAS24/KOG I, a component of the TOR complex I (TORCI), is needed for resistance to local anesthetic tetracaine and normal distribution of actin cytoskeleton in yeast. Genes Genet Syst 2005, 80:325-343.

4I. Dubouloz F, Deloche O, Wanke V, Cameroni E, De Virgilio C: The TOR and EGO protein complexes orchestrate microautophagy in yeast. Mol Cell 2005, I 9:15-26.

42. Wullschleger $\mathrm{S}$, Loewith $\mathrm{R}$, Hall MN: TOR signaling in growth and metabolism. Cell 2006, I 24:47|-484.

43. Aronova S, Wedaman K, Anderson S, Yates J III, Powers T: Probing the membrane environment of the TOR kinases reveals functional interactions between TORCI, actin, and membrane trafficking in Saccharomyces cerevisiae. Mol Biol Cell 2007, I 8:2779-2794.

44. Askree SH, Yehuda T, Smolikov S, Gurevich R, Hawk J, Coker C, Krauskopf A, Kupiec M, McEachern Ml: A genome-wide screen for Saccharomyces cerevisiae deletion mutants that affect telomere length. Proc Natl Acad Sci USA 2004, I 0 I:9515-9516.

45. Winzeler $E A$, Shoemaker $D D$, Astromoff $A$, Liang $H$, Anderson $K$ Andre B, Bangham R, Benito R, Boeke JD, Bussey H, Chu AM, Connelly C, Davis K, Dietrich F, Dow SW, El Bakkoury M, Foury F, Friend SH, Gentalen E, Giaever G, Hegemann JH, Jones T, Laub M, Liao H, Davis RW: Functional characterization of the $S$. cerevisiae genome by gene deletion and parallel analysis. Science 1999 , 285:901-906.

46. Gietz RD, Sugino A: New yeast $E$. coli shuttle vectors constructed with in vitro mutagenized yeast genes lacking sixbase pair restriction sites. Gene 1998, 74:255-269. 
47. Brandl CJ, Furlanetto AM, Martens JA, Hamilton KS: Characterization of NGGI, a novel yeast gene required for glucose repression of GAL4p-regulated transcription. EMBO J 1993, I 2:5255-5265.

48. Brachat $A$, Liebundguth $N$, Rebischung $C$, Lemire $S$, Schärer F, Hoepfner D, Demchyshyn V, Howald I, Düsterhöft A, Möstl D, Pöhlmann R, Kötter P, Hall MN, Wach A, Philippsen P: Analysis of deletion phenotypes and GFP fusions of 21 novel Saccharomyces cerevisiae open reading frames. Yeast 2000, 3:24I-253.

49. Tong AH, Boone C: Synthetic genetic array analysis in Saccharomyces cerevisiae. Methods Mol Biol 2006, 313:171-192.

50. Eisen MB, Spellman PT, Brown PO, Botstein D: Cluster analysis and display of genome-wide expression patterns. Proc Natl Acad Sci USA 1998, 95: 14863-148.

Publish with Bio Med Central and every scientist can read your work free of charge

"BioMed Central will be the most significant development for disseminating the results of biomedical research in our lifetime. "

Sir Paul Nurse, Cancer Research UK

Your research papers will be:

- available free of charge to the entire biomedical community

- peer reviewed and published immediately upon acceptance

- cited in PubMed and archived on PubMed Central

- yours - you keep the copyright

Submit your manuscript here:

http://www.biomedcentral.com/info/publishing_adv.asp
BioMedcentral 